\title{
RESEARCH
}

Open Access

\section{The combined effects of microglia activation and brain glucose hypometabolism in early-onset Alzheimer's disease}

Giacomo Tondo ${ }^{1,2 \dagger}$, Leonardo laccarino ${ }^{2,3 \dagger}$, Silvia Paola Caminiti ${ }^{1,2}$, Luca Presotto ${ }^{2,4}$, Roberto Santangelo ${ }^{5}$, Sandro lannaccone ${ }^{6}$, Giuseppe Magnani ${ }^{5}$ and Daniela Perani ${ }^{1,2,4^{*}}$ (i)

\begin{abstract}
Background: Early-onset Alzheimer's disease (EOAD) is characterized by young age of onset ( $<65$ years), severe neurodegeneration, and rapid disease progression, thus differing significantly from typical late-onset Alzheimer's disease. Growing evidence suggests a primary role of neuroinflammation in AD pathogenesis. However, the role of microglia activation in EOAD remains a poorly explored field. Investigating microglial activation and its influence on the development of synaptic dysfunction and neuronal loss in EOAD may contribute to the understanding of its pathophysiology and to subject selection in clinical trials. In our study, we aimed to assess the amount of neuroinflammation and neurodegeneration and their relationship in EOAD patients, through positron emission tomography (PET) measures of microglia activation and brain metabolic changes.

Methods: We prospectively enrolled 12 EOAD patients, classified according to standard criteria, who underwent standard neurological and neuropsychological evaluation, CSF analysis, brain MRI, and both $\left[{ }^{18} \mathrm{~F}\right]-\mathrm{FDG}$ PET and $\left[{ }^{11} \mathrm{C}\right]-$ (R)-PK11195 PET. Healthy controls databases were used for statistical comparison. [ $\left.{ }^{18} \mathrm{~F}\right]$-FDG PET brain metabolism in single subjects and as a group was assessed by an optimized SPM voxel-wise single-subject method. $\left[{ }^{11} \mathrm{C}\right]-\mathrm{PK} 11195$ PET binding potentials were obtained using reference regions selected with an optimized clustering procedure followed by a parametric analysis. We performed a topographic interaction analysis and correlation analysis in ADsignature metabolic dysfunctional regions and regions of microglia activation. A network connectivity analysis was performed using the interaction regions of hypometabolism and $\left[{ }^{11} \mathrm{C}\right]-\mathrm{PK} 11195$ PET BP increases.

Results: EOAD patients showed a significant and extended microglia activation, as $\left[{ }^{11} \mathrm{C}\right]-\mathrm{PK} 11195$ PET binding potential increases, and hypometabolism in typical AD-signature brain regions, i.e., temporo-parietal cortex, with additional variable frontal and occipital hypometabolism in the EOAD variants. There was a spatial concordance in the interaction areas and significant correlations between the two biological changes. The network analysis showed (Continued on next page)
\end{abstract}

\footnotetext{
* Correspondence: perani.daniela@hsr.it

${ }^{\dagger}$ Giacomo Tondo and Leonardo laccarino contributed equally to this work.

'School of Psychology, Vita-Salute San Raffaele University, Milan, Italy

${ }^{2}$ In Vivo Human Molecular and Structural Neuroimaging Unit, Division of

Neuroscience, IRCCS San Raffaele Scientific Institute, Milan, Italy

Full list of author information is available at the end of the article
}

C C The Author(s). 2020 Open Access This article is licensed under a Creative Commons Attribution 4.0 International License, which permits use, sharing, adaptation, distribution and reproduction in any medium or format, as long as you give appropriate credit to the original author(s) and the source, provide a link to the Creative Commons licence, and indicate if changes were made. The images or other third party material in this article are included in the article's Creative Commons licence, unless indicated otherwise in a credit line to the material. If material is not included in the article's Creative Commons licence and your intended use is not permitted by statutory regulation or exceeds the permitted use, you will need to obtain permission directly from the copyright holder. To view a copy of this licence, visit http://creativecommons.org/licenses/by/4.0/. The Creative Commons Public Domain Dedication waiver (http://creativecommons.org/publicdomain/zero/1.0/) applies to the data made available in this article, unless otherwise stated in a credit line to the data. 
(Continued from previous page)
a disruption of frontal connectivity induced by the metabolic/microglia effects.

Conclusion: The severe microglia activation characterizing EOAD and contributing to neurodegeneration may be a marker of rapid disease progression. The coupling between brain glucose hypometabolism and local immune response in AD-signature regions supports their biological interaction.

Keywords: Positron emission tomography, Early-onset Alzheimer's disease, $\left[{ }^{18} \mathrm{~F}\right]-\mathrm{FDG}$ PET, $\left[{ }^{11} \mathrm{C}\right]-(\mathrm{R})-\mathrm{PK} 11195$ PET, Microglia activation

\section{Introduction}

The pathological hallmarks of Alzheimer's disease (AD) include the extracellular beta-amyloid plaques and the intracellular neurofibrillary tangles, associated with neuronal and synaptic loss [1]. In the last decade, neuroinflammation mediated by microglia has been recognized to play a significant role in neurodegeneration and in AD pathogenesis [2]. However, whether neuroinflammation occurs as a causative or consequential factor in neurodegenerative processes is still an unsolved question [3].

Early-onset Alzheimer's disease (EOAD) is an AD subtype characterized by onset of symptoms before the age of 65 years, which accounts for about $5 \%$ of $\mathrm{AD}$ cases [4]. The clinical and pathological features of EOAD significantly differ from those of late-onset AD (LOAD), thus suggesting a possible distinct pathophysiology [5-7]. EOAD patients have a greater clinical severity and a faster disease progression than LOAD [8-11]. EOAD clinical presentation is atypical in more than one third of cases, manifesting with impairment of executive functions, visuo-spatial abilities, or language, in addition to the characteristic episodic memory impairment [12]. Clinical symptoms reflect the presence of more extensive pathology, including a higher number of amyloid and tau deposits, greater synaptic loss, and brain atrophy [13-15].

Positron emission tomography (PET) imaging allows an in vivo evaluation of both neurodegeneration and neuroinflammation, thus providing evidence for pathophysiology in neurodegenerative diseases. $\left[{ }^{18} \mathrm{~F}\right]$-Fluorodeoxyglucose (FDG) PET is a topographical marker of brain glucose metabolism well representing the pattern of neurodegeneration in $\mathrm{AD}$, in $\mathrm{AD}$ variants, and other neurodegenerative conditions [16-18], even in the prodromal phases [19-22]. The characteristic brain hypometabolism involving the associative temporo-parietal cortices, the precuneus and posterior cingulate cortex, is the distinctive dysfunctional pattern of $\mathrm{AD}$ since the early stage of the disease. In EOAD, $\left[{ }^{18} \mathrm{~F}\right]$-FDG PET imaging studies showed, at a comparable level of clinical severity, a greater brain hypometabolism than in LOAD [5, 23-25] and an extension of the hypometabolism in frontal and occipital regions in atypical presentations $[26,27]$. More recently, $\left[{ }^{18} \mathrm{~F}\right]$-FDG PET measures have been used for the evaluation of brain metabolic connectivity [28]. $\left[{ }^{18} \mathrm{~F}\right]-$ FDG PET brain glucose consumption reflects neuronal communication signaling, both locally and between distant brain regions, and is closely associated with functional connectivity [29]. Metabolic connectivity analysis relies on the assumption that regions whose metabolism is correlated are functionally interconnected [30]. The study of metabolic connectivity in AD has provided insights into the early changes in synaptic activity, by showing specific metabolic disconnections in $\mathrm{AD}$ dementia as well as in the prodromal phases [31, 32]. EOAD and LOAD showed distinct network features in comparison with healthy controls, with EOAD characterized by a more extensive and progressive alterations of connectivity [33].

Several tracers allow the in vivo study of neuroinflammation and, among these, the most used and validated is $\left[{ }^{11} \mathrm{C}\right]-(\mathrm{R})-\mathrm{PK} 11195$ (1-(2-chlorophenyl)-N-methyl-N-(1methylpropyl)-3-isoquinoline carboxamide). $\left[{ }^{11} \mathrm{C}\right]-(\mathrm{R})-$ PK11195 PET provides measures of microglial activation associated with mitochondrial overexpression of the 18 $\mathrm{kDa}$ translocator protein (TSPO), formerly known as peripheral benzodiazepine receptor [34]. Microglia are the resident immunocompetent cells of the central nervous system, activated in response to a variety of stimuli and in different pathological conditions, including neurodegeneration [35]. $\left[{ }^{11} \mathrm{C}\right]-(\mathrm{R})-\mathrm{PK} 11195$ PET has been adopted in several studies involving AD cohorts, showing an increased tracer binding especially in the temporo-parietal, occipital, and cingulate cortex [36]. The relationship between microglia activity and glucose metabolism in $\mathrm{AD}$ was investigated combining $\left[{ }^{11} \mathrm{C}\right]-(\mathrm{R})$ PK11195 and $\left[{ }^{18} \mathrm{~F}\right]$-FDG PET imaging, reporting a significant correlation between increased microglia activation and reduced glucose metabolism, both at baseline and over time. This finding suggests that neuroinflammation throughout the AD pathogenetic process is associated with synaptic dysfunction and glucose hypometabolism [37, 38]. Notably, studies employing a second generation TSPO tracer, $\left[{ }^{11} \mathrm{C}\right]-\mathrm{PBR} 28$, in both EOAD and LOAD, reported a significantly higher tracer binding in frontal and parietal regions at baseline and over time, correlating with clinical severity [39], as well as a greater annual $\left[{ }^{11} \mathrm{C}\right]-\mathrm{PBR} 28$ binding increase in temporo-parietal regions [40]. 
To date, the relationship between microglia activation and glucose hypometabolism in EOAD has not been investigated. Assessing the relationship between neuroinflammation and synaptic dysfunction in EOAD may contribute to the understanding of its pathophysiology and, possibly, to the selection of subjects for clinical trials. In our study, we hypothesized that microglia activation may play a significant role in EOAD neurodegeneration. Thus, we measured the correlation between microglia activation and glucose hypometabolism by using both $\left[{ }^{11} \mathrm{C}\right]$ (R)-PK11195 and $\left[{ }^{18} \mathrm{~F}\right]$-FDG PET in single EOAD patients and comparing the results with a normal control database. Crucially, we also investigated the effect of metabolismmicroglia spatial interaction in the modulation of network metabolic connectivity in the EOAD group.

\section{Methods}

\section{Participants}

Twelve patients with dementia, aged less than 65 years at disease onset, entered the study. They were admitted in the period from 2015 to 2017 to the Departments of Neurology and the Department of Rehabilitation and Functional Recovery, San Raffaele Hospital, Milan, Italy. All participants underwent a standard neurological evaluation by neurologists expert in evaluating dementia. Mini Mental State Evaluation (MMSE) and standard neuropsychological tests assessing memory, executive functions, language, and visuo-spatial abilities were obtained in all patients. Participants underwent blood analysis, lumbar puncture for cerebrospinal fluid analysis, brain MRI, and both $\left[{ }^{18} \mathrm{~F}\right]$-FDG PET and $\left[{ }^{11} \mathrm{C}\right]-(\mathrm{R})-\mathrm{PK} 11195$ PET. The PET scans were performed at the Nuclear Medicine Unit, San Raffaele Hospital, Milan, Italy.

The study was approved by the San Raffaele Hospital Ethical Committee. We obtained informed written consent from patients and patient designated informants in accordance with the Declaration of Helsinki.

\section{PET imaging acquisition}

The $\left[{ }^{18} \mathrm{~F}\right]$-FDG PET studies were acquired with a Discovery STE (GE Medical System, Milwaukee, WI) multi-ring PET tomography (PET-CT) system. Before radiopharmaceutical injection, patients were fasted for at least $6 \mathrm{~h}$ and their blood glucose level was $<120 \mathrm{mg} / \mathrm{dl}$. Scans were acquired in resting state, in a dark set with patients lying with closed eyes, starting $45 \mathrm{~min}$ after injecting 185-250 $\mathrm{MBq}$ of $\left[{ }^{18} \mathrm{~F}\right]$ FDG via a venous cannula. Image reconstruction was performed using an ordered subset expectation maximization (OSEM) algorithm. PET images were corrected for attenuation with a low-dose CT acquired contextually. Scatter correction was performed on all scans with the integrated software.

$\left[{ }^{11} \mathrm{C}\right]-(\mathrm{R})-\mathrm{PK} 11195$ PET scans were performed on multi-ring PET homographs, either PET-CT Discovery
LS or Discovery 690 general electric medical system (GEMS), injecting a dose of $380 \pm 37 \mathrm{MBq}$ of $\left[{ }^{11} \mathrm{C}\right]-(\mathrm{R})$ PK11195. [ $\left.{ }^{11} \mathrm{C}\right]-(\mathrm{R})-\mathrm{PK} 11195$ synthesis was performed in the Cyclotron Unit of the Nuclear Medicine of the San Raffaele Hospital as previously described [41], obtaining a radiochemical and chemical purity $>95 \%$. Acquisition protocol included a dynamic PET scan of 15 frames lasting $58 \mathrm{~min}(6 \times 30 \mathrm{~s} / 2 \times 1 \mathrm{~min} / 1 \times 3 \mathrm{~min} / 3 \times 5 \mathrm{~min} / 2 \times 10$ $\mathrm{min} / 1 \times 15 \mathrm{~min})$. PET data were corrected for attenuation artifacts, radioactive decay, and scatter. For each scan, movement correction was executed by realigning individual frames over time using the Statistical Parametric Mapping (SPM) 5 software (http://www.fil.ion. ucl.ac.uk/spm/software). $\left[{ }^{11} \mathrm{C}\right]-(\mathrm{R})-\mathrm{PK} 11195$ PET scans of nine healthy controls (HC) (mean age $43.6 \pm 11.2$ years) were included for statistical comparison.

\section{Imaging processing and data analysis \\ $\left[^{18}\right.$ F]-FDG-PET data processing}

Data analysis was performed according to standardized and validated procedures $[17,42]$. $\left[{ }^{18} \mathrm{~F}\right]$-FDG PET images were normalized at a single subject level using a dementia specific SPM FDG PET template [42], then smoothed with $8 \mathrm{~mm}$ full width at half maximum (FWHM) Gaussian kernel. Each patient scan was tested for relative hypometabolism by means of a two-sample $t$ test implemented in SPM12, based on validated procedure in which the single image is compared on a voxel-by-voxel basis with a large normal database $(N=112)$ of $\left[{ }^{18} \mathrm{~F}\right]-\mathrm{FDG}$ PET images [17], including age as covariate. We operated proportional scaling to eliminate inter-subject global variation in PET intensities. In the resulting SPM t-maps, a threshold was set at $P<0.05$ family wise error (FWE) corrected for multiple comparisons at the voxel level, considering significant clusters containing more than 100 voxels. We assessed EOAD hypometabolism pattern at the group level considering the same group of controls used for the single-subject analysis, performing a two-sample $t$ test (EOAD group vs. HC group) covarying for age as a nuisance factor, setting significant threshold at 0.001 uncorrected, and considering significant clusters containing more than 100 voxels.

\section{$\left[{ }^{11} \mathrm{C}\right]-(\mathrm{R})-\mathrm{PK} 11195-\mathrm{PET}$ data processing}

$\left[{ }^{11} \mathrm{C}\right]-(\mathrm{R})-\mathrm{PK} 11195$ binding potentials $\left(\mathrm{BP}_{\mathrm{s}}\right)$ were estimated adopting a receptor parametric mapping (RPM) procedure, requiring a pre-set reference region [43]. Given the heterogeneous distribution of $\left[{ }^{11} \mathrm{C}\right]-(\mathrm{R})-\mathrm{PK} 11195$ across the whole brain, hindering the delineation of a defined reference region, clustering methods have been proposed for PET studies of microglial activation. In our study, all the images were analyzed using the curve distance clustering algorithm (CDCA) [44], an adaptation of the validated SuperVised Clustering Algorithm [45]. The CDCA estimates the similarity of the time activity curve (TAC) of each voxel with 
four predefined TACs (tracer delivery in blood, white matter, grey matter with non-specific binding and high specific binding), allowing the selection of a cluster of voxels where the tracer kinetic is devoid of specific uptake. This pseudo-reference region can be used for the subsequent parametric analysis [44]. The clustering maps obtained with the CDCA method were warped to the standard Montreal Neurological Institute (MNI) space, then smoothed with $8 \mathrm{~mm}$ full width at half maximum (FWHM) Gaussian kernel. We explored voxelwise statistical differences between the EOAD group and 9 healthy controls group at single-subject and group levels. Analyses were run with SPM12 covarying for age as a nuisance factor setting statistical threshold at $P<0.01$ (uncorrected for multiple comparisons), considering significant those clusters containing more than 100 voxels.

\section{Interaction analysis}

To estimate the spatial interaction between hypometabolism and activated microglia, we considered binary masks of brain regional hypometabolism and microglial activation obtained from EOAD group vs. control groups in the voxel-wise comparisons. We obtained an interaction mask with IMcalc in SPM software applying the following formula:

Interaction mask $=\left[{ }^{18} \mathrm{~F}\right]$-FDG hypometabolism $\times\left[{ }^{11} \mathrm{C}\right]-$ (R)-PK11195 microglial activation

We extracted cerebral glucose metabolic rate (rCMRG1c) uptake and $\left[{ }^{11} \mathrm{C}\right]-(\mathrm{R})-\mathrm{PK} 11195$ BP from the interaction mask for each EOAD patient.

\section{Correlation analysis}

Correlation between $\left[{ }^{18} \mathrm{~F}\right]$-FDG hypometabolism and $\left[{ }^{11} \mathrm{C}\right]-(\mathrm{R})-\mathrm{PK} 11195 \mathrm{BP}$ was investigated using Spearman's rho correlation $(P<0.05)$. Statistical analysis was performed using IBM SPSS 22 (Statistical Package for Social Sciences software, IBM, Armonk, NY, USA).

\section{Brain network analysis}

A recent study investigating the association between $\left[{ }^{11} \mathrm{C}\right]-(\mathrm{R})-\mathrm{PK} 11195$ binding increase and functional connectivity in AD patients showed a strong association between higher levels of neuroinflammation and abnormal connectivity, correlating with worse cognitive dysfunction [46]. To examine whether the spatial interaction between hypometabolism and microglia activation might affect large-scale metabolic connectivity in EOAD, we performed seed-based intercorrelation analysis, a validated method to explore metabolic connectivity using $\left[{ }^{18} \mathrm{~F}\right]$-FDG PET [47]. We used the interaction mask, previously obtained (see the "Interaction analysis" section), as the seed volume of interest in order to perform the SPM voxel-wise interregional correlation analysis. Metabolic connectivity analysis was also performed in a group of 20 age- and sexmatched healthy controls (mean age $61.3 \pm 3.5$ years) for comparison.

\section{Results}

Twelve patients met clinical diagnostic criteria for probable early-onset $\mathrm{AD}$ [48]. Considering clinical, neuropsychological, imaging, and CSF data, four patients fulfilled the criteria for typical $\mathrm{AD}$ (tAD), six patients fulfilled the criteria for frontal $\mathrm{AD}$ (fAD) variant, and two patients were diagnosed as posterior cortical atrophy (PCA) variant [49]. Table 1 shows patients demographic and neuropsychological data.

\section{$\left[{ }^{18} \mathrm{~F}\right]$-FDG PET imaging findings}

The single subject procedure showed a consistent pattern of hypometabolism involving temporo-parietal regions, mainly in the right hemisphere, in all patients, with a variable involvement of occipital and frontal regions. A specific hypometabolic pattern of distribution was recognizable according to the clinical phenotype, namely frontal involvement in fAD patients and occipital hypometabolism in PCA patients (see Fig. 1). The single case presentation is included in the Additional file. The $\left[{ }^{18} \mathrm{~F}\right]$-FDG PET group analysis confirmed the presence of marked hypometabolism in temporo-parietal regions (see Fig. 2).

\section{$\left[{ }^{11} \mathrm{C}\right]-(\mathrm{R})-\mathrm{PK} 11195-\mathrm{PET}$ imaging findings}

The evaluation of the single subject $\left[{ }^{11} \mathrm{C}\right]-(\mathrm{R})-\mathrm{PK} 11195$ $\mathrm{BP}$ maps showed a variable and significant BPs increases in all EOAD patients, with major clusters of activation in temporal, parietal, occipital, and frontal regions (see Fig. 1). At a group level, there was a significant difference between regional $\left[{ }^{11} \mathrm{C}\right]-(\mathrm{R})-\mathrm{PK} 11195$ uptake in EOAD compared to $\mathrm{HC}$ bilaterally, in the middle inferior temporal gyrus, in the superior frontal gyrus, in the occipital gyrus, in the left precentral gyrus and left calcarine cortex, and in the right angular gyrus and right precuneus (see Fig. 2).

The single case presentation of clinical features, $\left[{ }^{18} \mathrm{~F}\right]-\mathrm{FDG}$ PET imaging findings, and increased $\left[{ }^{11} \mathrm{C}\right]-(\mathrm{R})-\mathrm{PK} 11195 \mathrm{BPs}$ are detailed in the Additional file.

\section{Interaction analysis}

The interaction analysis identified a spatial overlap in the right hemisphere temporo-parietal regions, namely in the inferior temporal gyrus, the precuneus, the angular gyrus, and the inferior parietal lobule. 


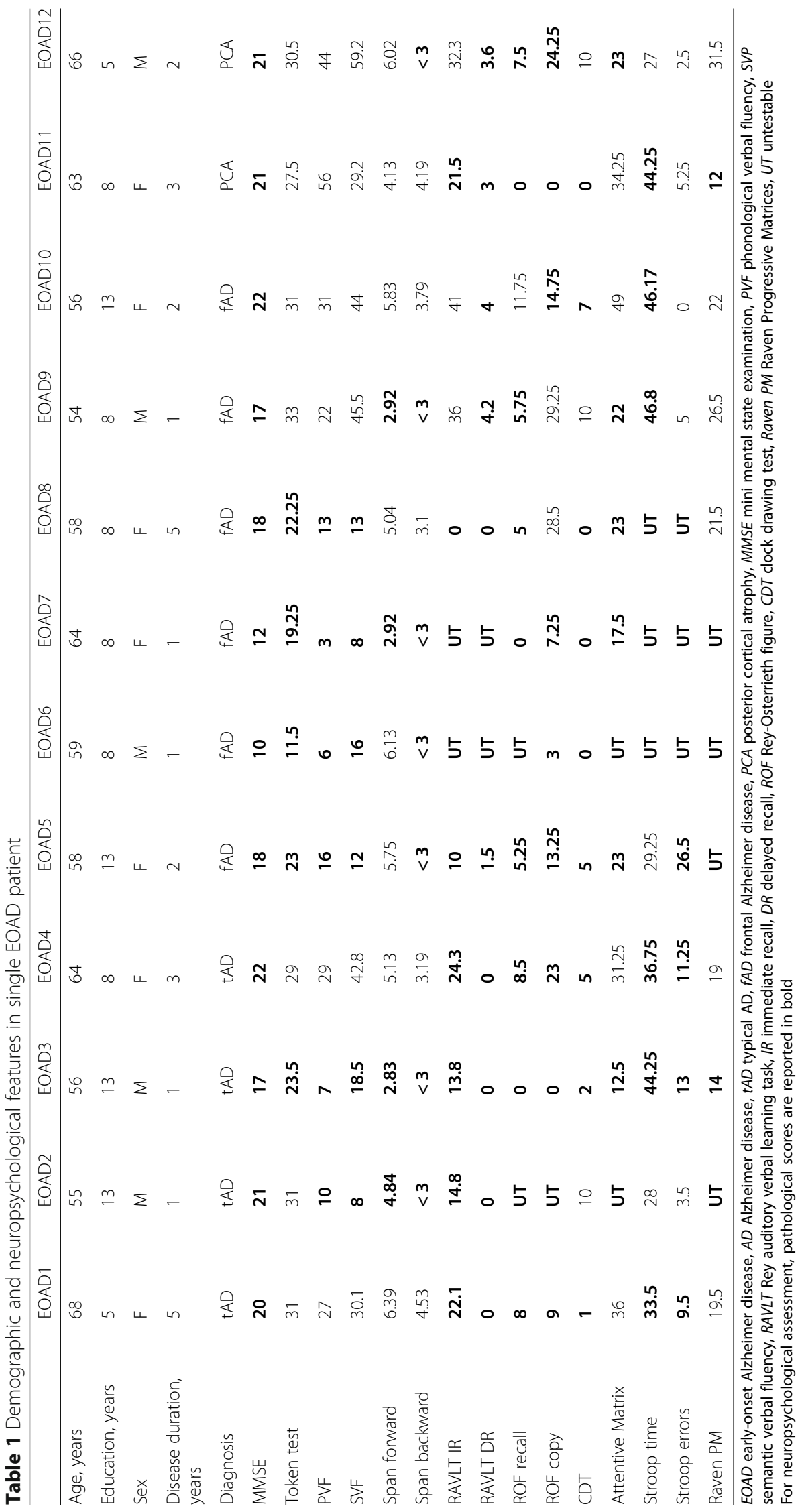




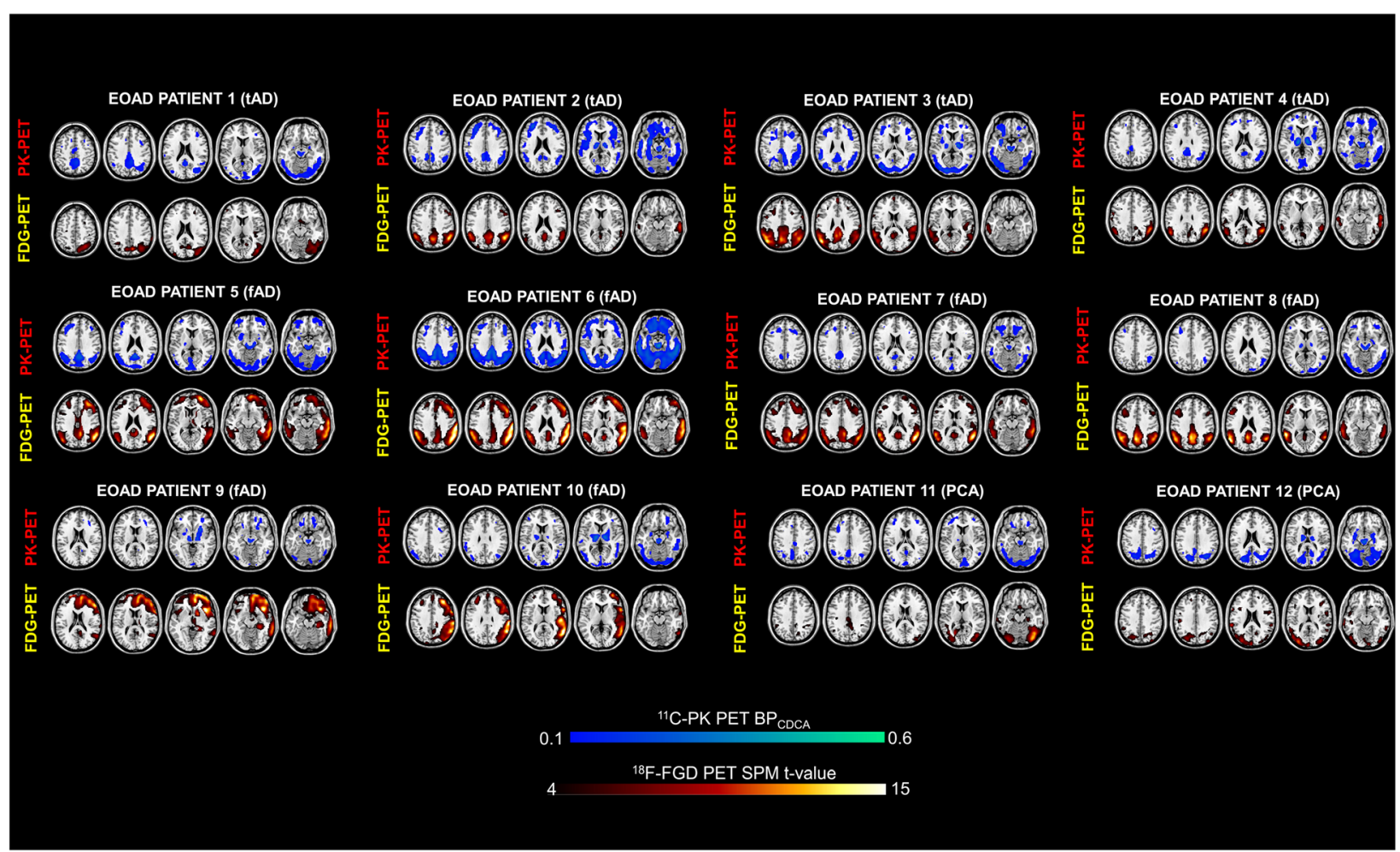

Fig. 1 Patterns of $\left[{ }^{18}\right.$ F]-FDG PET brain hypometabolism and $\left[{ }^{11} \mathrm{C}\right]-\mathrm{PK} 11195$ PET binding potential in single individuals. tAD, typical Alzheimer disease; fAD, frontal AD variant; PCA, posterior cortical atrophy variant. Color scales for FDG and PK levels of significance

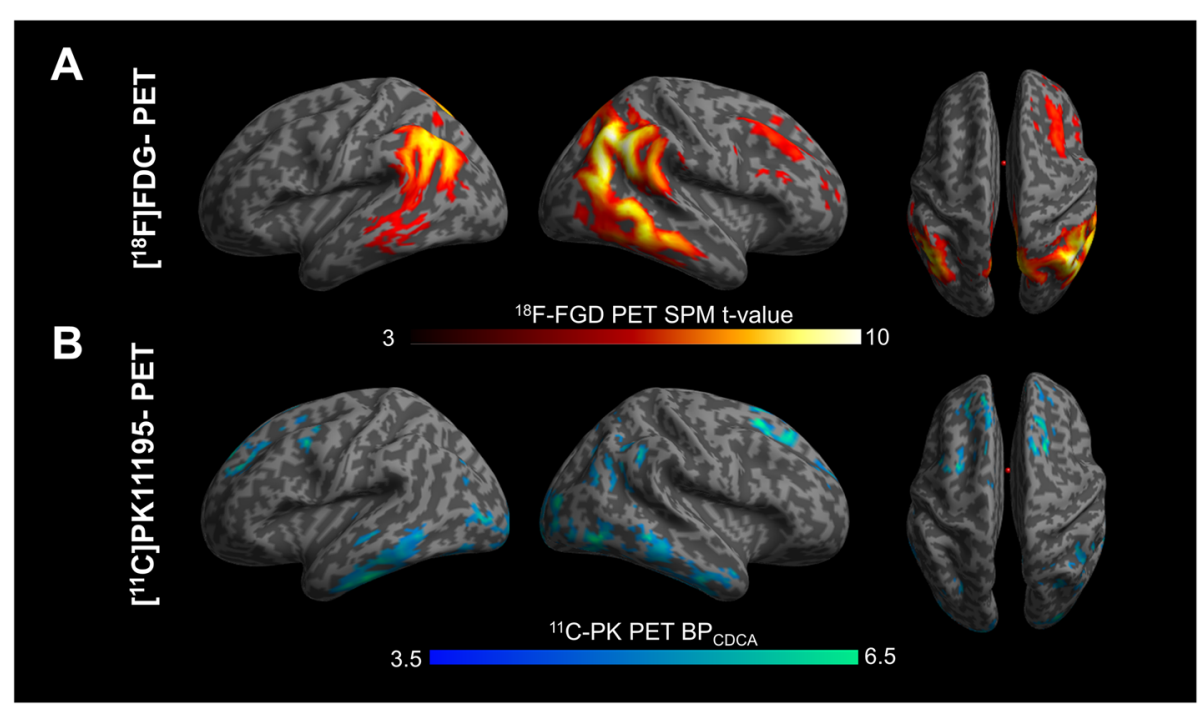

Fig. $2\left[{ }^{18} \mathrm{~F}\right]-\mathrm{FDG}$ PET and $\left[{ }^{11} \mathrm{C}\right]$-PK 11195 PET group analysis. The commonalities in the group comparison between early-onset Alzheimer's disease (EOAD) patients and healthy controls. $\mathbf{a}$ The pattern of brain hypometabolism and $\mathbf{b}$ the increased $\left[{ }^{11} \mathrm{C}\right]-(\mathrm{R})-\mathrm{PK} 11195$ binding potentials in the EOAD group. Results thresholded at $p<0.01$ uncorrected. Color scales for $\left[{ }^{18} \mathrm{~F}\right]$-FDG and $\left[{ }^{11} \mathrm{C}\right]-\mathrm{PK} 11195$ levels of significance 


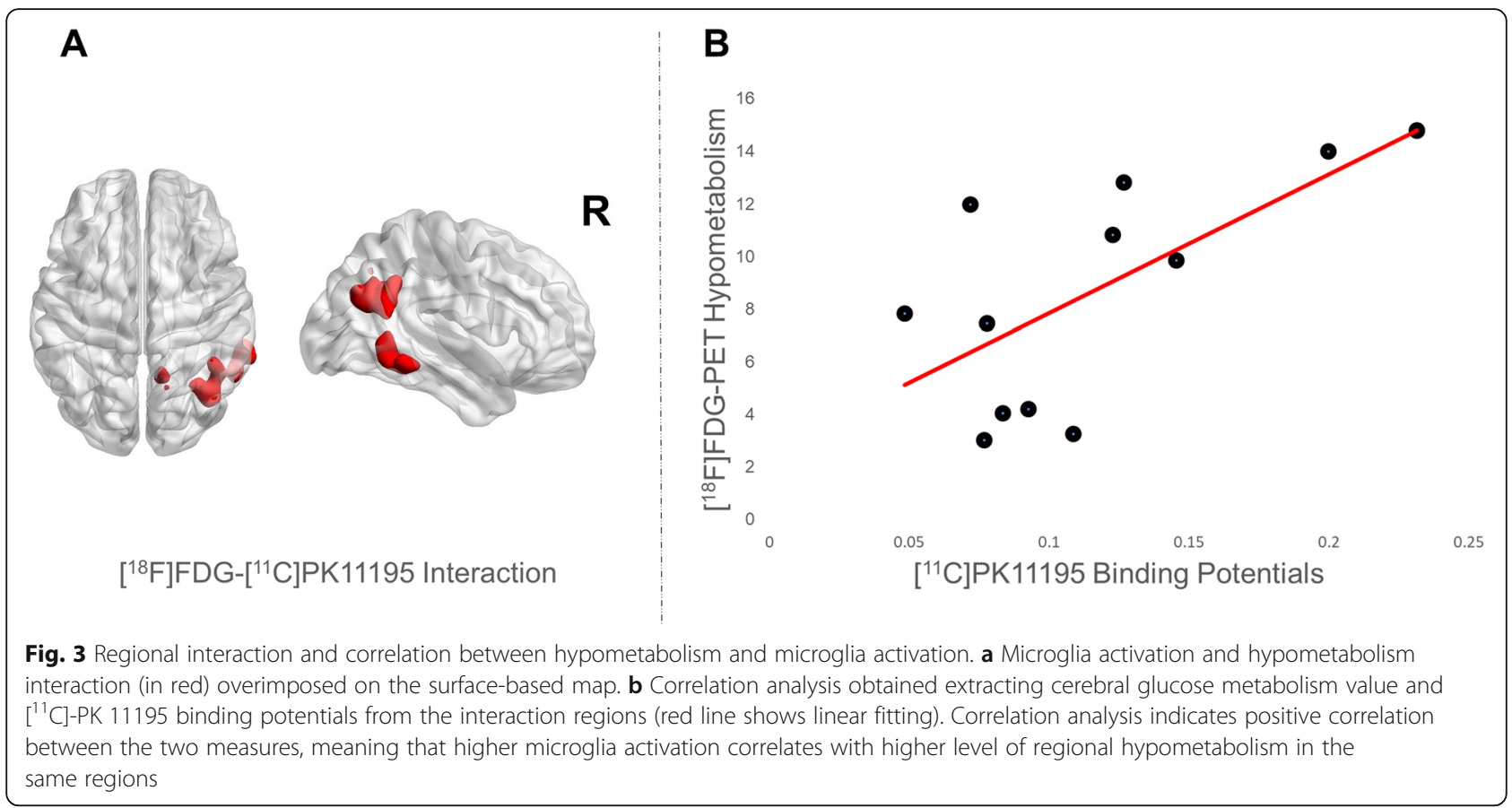

\section{Correlation analysis}

A higher microglial activation correlated with more severe hypometabolism in the same interaction regions $(r=0.667, p$ 0.018) (see Fig. 3 ).

\section{Network analysis}

Selecting as seed a region including the temporo-parietal interaction areas (see above), we identified an altered network in EOAD, mostly involving loss of connectivity between seed region and frontal cortex, in comparison with healthy subjects (see Fig. 4).

\section{Discussion}

This is the first study evaluating the relationship of brain glucose hypometabolism with microglia activation in a group of EOAD patients, using both $\left[{ }^{18} \mathrm{~F}\right]$-FDG and $\left[{ }^{11} \mathrm{C}\right]-$ (R)-PK11195 PET. We showed a significant and widespread microglial activation in EOAD compared to controls, which

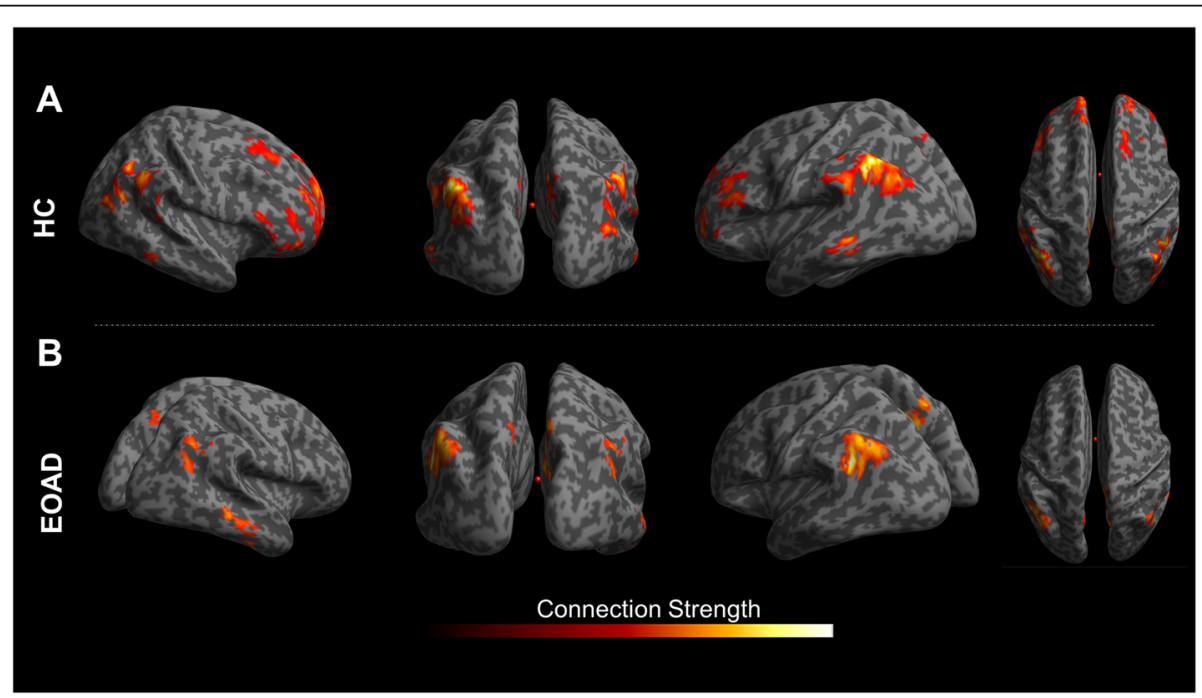

Fig. 4 Network analysis. a The brain network connectivity within the temporo-parietal and frontal regions in healthy controls (HC) and $\mathbf{b}$ the brain network connectivity in EOAD patients showing the frontal disconnection. Connection strength bar represents the t-values obtained by means of statistical parametric mapping (SPM) interregional correlation analysis (see text for details). The network connectivity is overlaid on a surface-based map 
had a spatial concordance with hypometabolism, mainly in $\mathrm{AD}$-signature regions, i.e., the temporo-parietal cortices, but involving also frontal and occipital regions. The latter finding might be related to the presence of frontal and occipital variants in our EOAD series. Consistent with previous data in EOAD, $\left[{ }^{18} \mathrm{~F}\right]$-FDG PET imaging analysis showed a typical hypometabolism involving temporoparietal region in all patients, with a variable involvement of frontal and occipital regions according to the clinical phenotype [24-26]. Coherently, in all fAD patients, there was also an involvement of frontal and prefrontal cortices, while PCA patients showed a hypometabolic pattern involving extensively the occipital regions.

Several PET studies using the radiotracer [11C]-(R)PK11195 showed that microglia activation may be an early phenomenon in $\mathrm{AD}[38,50-52]$ and that an increased uptake of $\left[{ }^{11} \mathrm{C}\right]-(\mathrm{R})-\mathrm{PK} 11195$ is related to the distribution of $\mathrm{AD}$ hypometabolism, involving in particular temporo-parietal and posterior cingulate regions $[50,52]$. Moreover, a recent in vivo study showed higher microglia activity in EOAD than in LOAD [40]. The role of microglial activation in EOAD, however, remains a scarcely explored field. In this study, we showed an increased $\left[{ }^{11} \mathrm{C}\right]-(\mathrm{R})-\mathrm{PK} 11195$ uptake in temporo-parietal, occipital, and frontal regions, as the common inflammatory pattern within the group. The increased $\left[{ }^{11} \mathrm{C}\right]-(\mathrm{R})$ PK11195 uptake showed an inter-subject variability in the single-subject analysis (Fig. 1). Notably, the frontal regional involvement in patients with fAD variant, and the posterior regions in the patients with PCA variant, suggest that a different pattern of neuroimmune activation may exist according to the clinical phenotype, as reported also in a previous work using $\left[{ }^{11} \mathrm{C}\right]-\mathrm{PBR} 28$, a second generation TSPO tracer [53].

The precise role of microglia in $\mathrm{AD}$ pathogenesis is still debated. In normal function, microglia activity is crucial in protection against pathologic protein accumulation, e.g., favoring also amyloid clearance [54]. On the other hand, a chronic activation of microglia is likely to contribute to neurodegeneration [3]. Although the mechanisms inducing a detrimental microglial activation and subsequent neurodegeneration are not fully understood, synaptic dysfunction and neuronal loss may be due to different pathologic processes, such as the failure in clearance of amyloid plaques and cellular debris, the release of proinflammatory cytokines [55] or to a direct neuronal damage and phagocytosis, which has been reported in living neurons of a mice model of tauopathy [56].

In our study, all patients showed a spatial concordance/interaction between microglial activation and hypometabolism in AD-signature regions, peaking in the right temporo-parietal cortex. Previous studies in AD showed a correlation between microglial activation and markers of neurodegeneration, such as glucose brain hypometabolism and atrophy, or AD pathology markers, such as amyloid load [37, 38, 51]. The positive correlation between $\left[{ }^{11} \mathrm{C}\right]-(\mathrm{R})-\mathrm{PK} 11195$ BPs and hypometabolism SPM maps and the spatial interaction between the two biological markers support the hypothesis of a relationship between microglial activation and neuronal synaptic dysfunction. Previous findings support the role of increased $\left[{ }^{11} \mathrm{C}\right]-(\mathrm{R})-\mathrm{PK} 11195$ BPs in neuronal damage, given its correlation with global cognitive severity [51].

Considering as seed the regional interaction of microglial activation and hypometabolism, we found a longdistance loss of connectivity between temporo-parietal seed and frontal cortex, in comparison with the integrity of the same network relating parietal, occipital, and frontal regions in healthy controls. Regional microglial activation might negatively affect long-distance network organization, thus representing a relevant pathological event contributing to the neuronal damage and faster clinical progression typical of EOAD. A recent study investigating microglial activation and functional connectivity in $\mathrm{AD}$ suggested that neuroinflammation may be involved in pathophysiological changes in network function underlying cognitive deficits [46]. Our study confirms these only findings, suggesting that microglial activation may represent an early detrimental response in EOAD, underpinning an ongoing pathology in functionally connected regions in addition to the local damage, all driven by the neuroinflammation processes.

Our findings are limited by the small number of patients and by the inability of $\left[{ }^{11} \mathrm{C}\right]-(\mathrm{R})-\mathrm{PK} 11195$ PET to distinguish among different microglia populations. Nevertheless, $\left[{ }^{11} \mathrm{C}\right]-(\mathrm{R})-\mathrm{PK} 11195$ PET has been widely used in neurodegenerative conditions, showing consistent results [36].

\section{Conclusions}

Previous studies showed that EOAD patients have more severe clinical manifestations than LOAD [9] and a greater hypometabolism and connectivity dysfunction [27]. Our study crucially adds that microglial activation may strongly contribute to neuronal damage in EOAD, providing new insights in the understanding of the underlying pathophysiology processes. In our sample, all EOAD patients show a coupled microglial activation and reduced glucose hypometabolism in key neurodegeneration regions for $\mathrm{AD}$, with correlations between the two biological markers. Hypometabolism and neuroinflammation may thus act in a dynamic way, priming a vicious circle leading to faster clinical decline.

\section{Supplementary information}

Supplementary information accompanies this paper at https://doi.org/10. 1186/s13195-020-00619-0.

\section{Additional file 1.}




\section{Abbreviations}

AD: Alzheimer's disease; EOAD: Early-onset Alzheimer's disease; LOAD: Lateonset Alzheimer's disease; tAD: Typical Alzheimer's disease; fAD: Frontal Alzheimer's disease; PCA: Posterior cortical atrophy; HC: Healthy controls; PET: Positron emission tomography; FDG: Fluorodeoxyglucose; TSPO: 18 kDa translocator protein; SPM: Statistical Parametric Mapping; CDCA: Curve distance clustering algorithm; TAC: Time activity curve; BP: Binding potentia

\section{Acknowledgements}

Not applicable.

\section{Authors' contributions}

DP was responsible for the design and conceptualization of the study, performed the data interpretation, and drafted and revised the manuscript. GT, LI, SPC, and LP performed the analysis and interpretation of the data for the work and drafted the manuscript. RS, SI, and GM performed the acquisition of the data and drafted and revised the manuscript. All authors read and approved the final manuscript.

\section{Funding}

This work was supported by EU FP7 INMIND Project spiepr132 (FP7spiepr132 HEALTH-2013, grant agreement no.spiepr146 278850), by the Italian Ministry of Health (Ricerca Finalizzata Progetto Reti Nazionale AD NET2011-02346784), and by the IVASCOMAR project "Identificazione, validazione e sviluppo commerciale di nuovi biomarcatori diagnostici prognostici per malattie complesse" (grant agreement no.spiepr146 CTN01_00177_165430).

\section{Availability of data and materials}

The datasets used and/or analyzed during the current study are available from the corresponding author on reasonable request.

\section{Ethics approval and consent to participate}

The study was approved by the San Raffaele Hospital Ethical Committees (ref num 72/2012.int). Informed consent was obtained from each subject or relatives; the protocols conformed to the Ethical standards of the declaration of Helsinki for protection of human subjects.

\section{Consent for publication}

All patients and/or caregivers gave written informed consent to the study/ data treatment for scientific purposes, including publications. The informed consents are available from the corresponding author on request. All the reported data are anonymized, and no patient can be identified by the reported data.

\section{Competing interests}

The authors declare that they have no competing interests.

\section{Author details}

${ }^{1}$ School of Psychology, Vita-Salute San Raffaele University, Milan, Italy. ${ }^{2}$ In Vivo Human Molecular and Structural Neuroimaging Unit, Division of Neuroscience, IRCCS San Raffaele Scientific Institute, Milan, Italy. ${ }^{3}$ Memory and Aging Center, Department of Neurology, Weill Institute for Neurosciences, University of California, San Francisco, CA, USA. ${ }^{4}$ Nuclear Medicine Unit, San Raffaele Hospital, Milan, Italy. ${ }^{5}$ Department of Neurology and INSPE, San Raffaele Scientific Institute, Milan, Italy. ${ }^{6}$ Clinical Neuroscience Department, San Raffaele Turro Hospital, Milan, Italy.

Received: 31 August 2019 Accepted: 22 April 2020

Published online: 30 April 2020

\section{References}

1. Masters CL, Bateman R, Blennow K, Rowe CC, Sperling RA, Cummings JL. Alzheimer's disease. Nat Rev Dis Prim. 2015;1:15056. https://doi.org/10.1038/ nrdp.2015.56.

2. Ransohoff RM. How neuroinflammation contributes to neurodegeneration. Science (80- ). 2016;353(6301):777-83.

3. Sochocka M, Diniz BS, Leszek J. Inflammatory response in the CNS: friend or foe? Mol Neurobiol. 2017:54(10):8071-89.

4. Winblad B, Amouyel P, Andrieu S, et al. Defeating Alzheimer's disease and other dementias: a priority for European science and society. Lancet Neurol. 2016;15(5):455-532.
5. Kaiser NC, Melrose RJ, Liu C, et al. Neuropsychological and neuroimaging markers in early versus late-onset Alzheimer's disease. Am J Alzheimer's Dis Other Dementias $^{\circledast}$. 2012;27(7):520-9.

6. Smits LL, Pijnenburg YAL, Koedam ELGE, et al. Early onset Alzheimer's disease is associated with a distinct neuropsychological profile. J Alzheimers Dis. 2012;30(1):101-8.

7. Sá F, Pinto P, Cunha C, et al. Differences between early and late-onset Alzheimer's disease in neuropsychological tests. Front Neurol. 2012;3:81.

8. Panegyres PK, Chen H-Y. Differences between early and late onset Alzheimer's disease. Am J Neurodegener Dis. 2013;2(4):300.

9. Stanley K, Walker Z. Do patients with young onset Alzheimer's disease deteriorate faster than those with late onset Alzheimer's disease? A review of the literature. Int Psychogeriatrics. 2014;26(12):1945-53.

10. Wattmo C, Wallin ÅK. Early-versus late-onset Alzheimer's disease in clinical practice: cognitive and global outcomes over 3 years. Alzheimers Res Ther. 2017:9(1):70.

11. Mendez MF. Early-onset Alzheimer disease and its variants. Contin Lifelong Learn Neurol. 2019;25(1):34-51.

12. Balasa M, Gelpi E, Antonell A, et al. Clinical features and APOE genotype of pathologically proven early-onset Alzheimer disease. Neurology. 2011;76(20): 1720-5.

13. Bigio EH, Hynan LS, Sontag E, Satumtira S, White CL III. Synapse loss is greater in presenile than senile onset Alzheimer disease: implications for the cognitive reserve hypothesis. Neuropathol Appl Neurobiol. 2002;28(3):218-27.

14. Palasí A, Gutiérrez-Iglesias B, Alegret $M$, et al. Differentiated clinica presentation of early and late-onset Alzheimer's disease: is 65 years of age providing a reliable threshold? J Neurol. 2015;262(5):1238-46.

15. Frisoni GB, Testa C, Sabattoli F, Beltramello A, Soininen H, Laakso MP. Structural correlates of early and late onset Alzheimer's disease: voxel based morphometric study. J Neurol Neurosurg Psychiatry. 2005;76(1):112-4.

16. Cerami C, Dodich A, Greco L, et al. The role of single-subject brain metabolic patterns in the early differential diagnosis of primary progressive aphasias and in prediction of progression to dementia. J Alzheimers Dis. 2017:55(1):183-97.

17. Perani D, Della Rosa PA, Cerami C, et al. Validation of an optimized SPM procedure for FDG-PET in dementia diagnosis in a clinical setting. Neurolmage Clin. 2014;6:445-54. https://doi.org/10.1016/j.nicl.2014.10.009.

18. Vanhoutte M, Lopes R, Maureille A, et al. Hypometabolism patterns using FDG PET in typical and atypical sporadic forms of early-onset Alzheimer's disease. Alzheimers Dement. 2016;12(7):P532. https://doi.org/10.1016/j.jalz.2016.06.1041.

19. Caminiti SP, Ballarini T, Sala A, et al. FDG-PET and CSF biomarker accuracy in prediction of conversion to different dementias in a large multicentre $\mathrm{MCl}$ cohort. Neurolmage Clin. 2018;18:167-77.

20. laccarino L, Chiotis K, Alongi $P$, et al. A cross-validation of FDG-and amyloidPET biomarkers in mild cognitive impairment for the risk prediction to dementia due to Alzheimer's disease in a clinical setting. J Alzheimers Dis. 2017:59(2):603-14

21. Perani D, Cerami C, Caminiti SP, et al. Cross-validation of biomarkers for the early differential diagnosis and prognosis of dementia in a clinical setting. Eur J Nucl Med Mol Imaging. 2016;43(3):499-508.

22. Cerami C, Della Rosa PA, Magnani G, et al. Brain metabolic maps in mild cognitive impairment predict heterogeneity of progression to dementia. Neurolmage Clin. 2015:7:187-94.

23. Rabinovici GD, Furst AJ, Alkalay A, et al. Increased metabolic vulnerability in early-onset Alzheimer's disease is not related to amyloid burden. Brain. 2010;133(2):512-28.

24. Chiaravalloti A, Koch G, Toniolo S, et al. Comparison between early-onset and late-onset Alzheimer's disease patients with amnestic presentation: CSF and 18F-FDG PET study. Dement Geriatr Cogn Dis Extra. 2016:6(1):108-19.

25. Kim EJ, Cho SS, Jeong Y, et al. Glucose metabolism in early onset versus late onset Alzheimer's disease: an SPM analysis of 120 patients. Brain. 2005; 128(8):1790-801.

26. Vanhoutte M, Semah F, Sillaire AR, et al. 18F-FDG PET hypometabolism patterns reflect clinical heterogeneity in sporadic forms of early-onset Alzheimer's disease. Neurobiol Aging. 2017;59:184-96.

27. Ballarini T, laccarino L, Magnani $G$, et al. Neuropsychiatric subsyndromes and brain metabolic network dysfunctions in early onset Alzheimer's disease. Hum Brain Mapp. 2016:37(12):4234-47.

28. Sala A, Perani D. Brain molecular connectivity in neurodegenerative diseases: recent advances and new perspectives using positron emission tomography. Front Neurosci. 2019;13:617. 
29. Passow S, Specht K, Adamsen TC, et al. Default-mode network functional connectivity is closely related to metabolic activity. Hum Brain Mapp. 2015; 36(6):2027-38.

30. Horwitz B, Duara R, Rapoport SI. Intercorrelations of glucose metabolic rates between brain regions: application to healthy males in a state of reduced sensory input. J Cereb Blood Flow Metab. 1984;4(4):484-99.

31. Morbelli S, Drzezga A, Perneczky R, et al. Resting metabolic connectivity in prodromal Alzheimer's disease. A European Alzheimer Disease Consortium (EADC) project. Neurobiol Aging. 2012;33(11):2533-50.

32. Malpetti $M$, Ballarini $T$, Presotto $L$, et al. Gender differences in healthy aging and Alzheimer's dementia: a 18F-FDG-PET study of brain and cognitive reserve. Hum Brain Mapp. 2017;38(8):4212-27.

33. Chung J, Yoo K, Kim E, Na DL, Jeong Y. Glucose metabolic brain networks in early-onset vs late-onset Alzheimer's disease. Front Aging Neurosci. 2016;8:159.

34. Papadopoulos V, Baraldi M, Guilarte TR, et al. Translocator protein (18 kDa): new nomenclature for the peripheral-type benzodiazepine receptor based on its structure and molecular function. Trends Pharmacol Sci. 2006;27(8): 402-9.

35. Amor S, Puentes F, Baker D, Van Der Valk P. Inflammation in neurodegenerative diseases. Immunology. 2010;129(2):154-69.

36. Cerami $C$, laccarino $L$, Perani D. Molecular imaging of neuroinflammation in neurodegenerative dementias: the role of in vivo PET imaging. Int J Mol Sci. 2017;18(5):993

37. Fan Z, Okello AA, Brooks DJ, Edison P. Longitudinal influence of microglial activation and amyloid on neuronal function in Alzheimer's disease. Brain. 2015;138(12):3685-98.

38. Fan Z, Aman Y, Ahmed I, et al. Influence of microglial activation on neuronal function in Alzheimer's and Parkinson's disease dementia. Alzheimers Dement. 2015;11(6):608-21.

39. KreisI WC, Lyoo CH, MCGwier M, et al. In vivo radioligand binding to translocator protein correlates with severity of Alzheimer's disease. Brain 2013;136(7):2228-38.

40. Kreisl WC, Lyoo CH, Liow J, et al. 11C-PBR28 binding to translocator protein increases with progression of Alzheimer's disease. Neurobiol Aging. 2016;44:53-61.

41. Matarrese M, Moresco RM, Cappelli A, et al. Labeling and evaluation of N[11C] methylated quinoline-2-carboxamides as potential radioligands for visualization of peripheral benzodiazepine receptors. J Med Chem. 2001; 44(4):579-85.

42. Della Rosa PA, Cerami C, Gallivanone F, et al. A standardized [18 F]-FDG-PET template for spatial normalization in statistical parametric mapping of dementia. Neuroinformatics. 2014;12(4):575-93.

43. Gunn RN, Lammertsma AA, Hume SP, Cunningham VJ. Parametric imaging of ligand-receptor binding in PET using a simplified reference region model. Neuroimage. 1997;6(4):279-87.

44. Presotto L, laccarino L, Bettinardi V, Gianolli L, Perani D. An automated clustering algorithm for reference region extraction of brain 11 C-PK11195 studies. In: 2015 IEEE nuclear science symposium and medical imaging conference (NSS/MIC). IEEE; 2015:1-3.

45. Turkheimer FE, Edison $\mathrm{P}$, Pavese $\mathrm{N}$, et al. Reference and target region modeling of [11C]-(R)-PK11195 brain studies. J Nucl Med. 2007:48(1):158-67.

46. Passamonti L, Tsvetanov KA, Jones PS, et al. Neuroinflammation and functional connectivity in Alzheimer's disease: interactive influences on cognitive performance. J Neurosci. 2019. doi: https://doi.org/10.1523/ JNEUROSCI.2574-18.2019.

47. Lee DS, Kang H, Kim H, et al. Metabolic connectivity by interregional correlation analysis using statistical parametric mapping (SPM) and FDG brain PET; methodological development and patterns of metabolic connectivity in adults. Eur J Nucl Med Mol Imaging. 2008;35(9):1681-91.

48. McKhann GM, Knopman DS, Chertkow H, et al. The diagnosis of dementia due to Alzheimer's disease: recommendations from the National Institute on Aging-Alzheimer's Association workgroups on diagnostic guidelines for Alzheimer's disease. Alzheimers Dement. 2011;7(3):263-9.

49. Dubois B, Feldman $\mathrm{HH}$, Jacova $\mathrm{C}$, et al. Advancing research diagnostic criteria for Alzheimer's disease: the IWG-2 criteria. Lancet Neurol. 2014;13(6): 614-29.

50. Cagnin A, Brooks DJ, Kennedy AM, et al. In-vivo measurement of activated microglia in dementia. Lancet. 2001;358(9280):461-7.
51. Edison P, Archer HA, Gerhard A, et al. Microglia, amyloid, and cognition in Alzheimer's disease: an [11C](R) PK11195-PET and [11C] PIB-PET study. Neurobiol Dis. 2008;32(3):412-9.

52. Yokokura M, Mori N, Yagi S, et al. In vivo changes in microglial activation and amyloid deposits in brain regions with hypometabolism in Alzheimer's disease. Eur J Nucl Med Mol Imaging. 2011;38(2):343-51.

53. Kreisl WC, Lyoo CH, Liow J-S, et al. Distinct patterns of increased translocator protein in posterior cortical atrophy and amnestic Alzheimer's disease. Neurobiol Aging. 2017;51:132-40.

54. Lee CYD, Landreth GE. The role of microglia in amyloid clearance from the AD brain. J Neural Transm. 2010;117(8):949-60.

55. Heneka MT, Carson MJ, El Khoury J, et al. Neuroinflammation in Alzheimer's disease. Lancet Neurol. 2015;14(4):388-405.

56. Brelstaff J, Tolkovsky AM, Ghetti B, Goedert M, Spillantini MG. Living neurons with tau filaments aberrantly expose phosphatidylserine and are phagocytosed by microglia. Cell Rep. 2018;24(8):1939-48.

\section{Publisher's Note}

Springer Nature remains neutral with regard to jurisdictional claims in published maps and institutional affiliations.
Ready to submit your research? Choose BMC and benefit from:

- fast, convenient online submission

- thorough peer review by experienced researchers in your field

- rapid publication on acceptance

- support for research data, including large and complex data types

- gold Open Access which fosters wider collaboration and increased citations

- maximum visibility for your research: over $100 \mathrm{M}$ website views per year

At $\mathrm{BMC}$, research is always in progress.

Learn more biomedcentral.com/submissions 